\title{
INFLUÊNCIA DA GESTÃO DE UMA EMPRESA NA ALAVANCAGEM DAS EXPORTAÇÕES: ESTUDO DE CASO NA MINA BREJUÍ
}

\author{
Rodrigo Ranieri Andrade Bacelar Felipe Sousa \\ Tecnólogo em Comércio Exterior pelo CEFET - RN (2007) e Graduando em \\ Administração pela UFRN. E-mail: rodi_rani@ hotmail.com. \\ Gerda Lúcia Pinheiro Camelo \\ Graduação em Administração de Empresas (1989) e em Ciências Contábeis pela \\ Universidade de Fortaleza (1985).gerda@ cefetrn.br
}

\begin{abstract}
RESUMO
A presente monografia vem com o intuito de fazer uma breve abordagem no formato de gestão empresarial de uma empresa mineradora que atua na exploração e exportação da scheelita. Foi feito um levantamento histórico da mineração no Brasil e no Rio Grande do Norte, enfocando na sequiência a exploração da scheelita, principal mineral na composição do tungstênio, o qual é de grande importância para inúmeras indústrias. Tendo como objetivo geral à percepção da influencia da gestão empresarial da Mineradora Tomaz Salustino S/A com retomada das exportações do produto. Como metodologia aplicada para o desenvolvimento do trabalho foi utilizado um estudo exploratório-descritivo através de levantamentos de dados em campo e pesquisas bibliográficas. Deixando como resultado uma trilha ao caminho do aperfeiçoamento e compreensão da atividade e suas mudanças, e isso se torna possível a partir da conjugação de constatações e considerações acerca do histórico e das atuais condições internas da empresa.
\end{abstract}

PALAVRAS-CHAVE: Gestão Empresarial, Scheelita, Exportação.

\section{INFLUENCE OF THE ADMINISTRATION OF A COMPANY IN GROWTH OF THE EXPORTS: STUDY OF CASE IN THE MINA BREJUÍ}

\begin{abstract}
The present monograph comes with intention to make a soon brief boarding in the format of entrepreneurship of a mining company who acts in the exploration and exportation of the scheelita. A historical survey of the mining in Brazil and Rio Grande do Norte was made, focusing in the sequence the scheelita's exploration, main mineral in the composition of the tungsten, which is of great importance for many industries. Having as objective generality to the perception of it influences of the entrepreneurship of the Mining Tomaz Salustino S/A with of the exportations of the product. As methodology applied for the development of the monograph a study was applied descriptive exploratory through data-collecting in field and bibliographical research. As result was left a track to the way of the perfectioning and understanding of the activity and its changes, this became possible since the junction of certifications and considerations about the historical and the current internal conditions of the company.
\end{abstract}

KEY-WORDS: Enterprise Management, Scheelita, Exportation 


\section{INFLUÊNCIA DA GESTÃO DE UMA EMPRESA NA ALAVANCAGEM DAS EXPORTAÇÕES: ESTUDO DE CASO NA MINA BREJUÍ}

\section{INTRODUÇÃO}

Dentre os vários segmentos existentes no mercado nacional, os quais continuam sendo afetados de forma profunda pela complexidade das mudanças que se processam, o presente trabalho focou um em especifico: o do setor mineral.

A mineração é uma prática antiga no mundo e que contribui muito com o desbravamento de inúmeras regiões, favorecendo assim a colonização e desenvolvimento das mesmas. Atualmente a importância da mineração esta focada no que tange o desenvolvimento de um país, pois o desenvolvimento industrial de uma nação está relacionado a sua produção mineral, tendo em vista o uso intensivo dos mesmos nos mais diversos ramos industriais. Sendo assim é observado que para uma empresa mineradora, a qual esta inserida nesse contexto globalizado atual, possa continuar a ter prosperidade com seu trabalho deverá adequar-se ao tempo e espaço que ela esta integrada. Portanto técnicas, ações e gestões que as empresas mais antigas detinham, atualmente - na maioria dos casos - não são mais aplicáveis, devido as constantes mudanças que esse novo mercado proporciona. Mudanças essas que não ocorrem apenas em âmbito nacional, mas também em âmbito internacional, devido a maior ligação entre as economias dos países nesse mercado globalizado.

O setor mineral no Brasil possui amplas reservas dos mais variados produtos. Segundo estudo do setor mineral brasileiro elaborado pela Gerência Setorial de Mineração e Metalurgia, a exploração dos minerais metálicos e de minerais industriais para construção civil são atividades onde o país apresenta uma indústria consolidada com empresas de nível internacional. Também relata que a mineração brasileira ainda se apresenta muito tímida, se comparada ao restante do mundo e ao grande potencial geológico do país.

Vêem-se disputas bastante acirradas nesse setor, principalmente no mercado internacional, tendo em vista as várias utilidades dos minerais para a sociedade atual. Pode-se tomar como exemplo de mineral de grande importância nas mais diversas indústrias o tungstênio, o qual é abundantemente encontrado na scheelita. Este último é encontrado em maiores quantidades no Nordeste do Brasil, sendo mais abundante no Rio Grande do Norte e Paraíba. Segundo o Departamento Nacional de Produção Mineral (DNPM) ${ }^{1}$ o mercado de tungstênio vive, atualmente, um momento ímpar, com o aumento expressivo dos preços desse mineral, decorrente da escassez da oferta e da grande demanda da China, semelhante ao que ocorre com as demais commodities minerais. O preço do mineral triplicou em três anos, proporcionando a viabilidade econômica de vários depósitos de scheelita, o que abre novas perspectivas de investimentos na região do Seridó, localizada no estado potiguar, importante província mineral do país. O tungstênio tem sua aplicabilidade nos mais diversos segmentos da industria, tais como: nas indústria bélica, espacial, siderúrgica, química, elétrica, eletrônica e mecânica.

\footnotetext{
${ }^{1}$ Dados disponíveis em www.dnpm.com.br.
} 
Segundo a Mineradora Tomaz Salustino S/A², a exploração da scheelita brasileira estava quase na sua totalidade paralisada em decorrência, principalmente, pela queda do preço do minério de tungstênio no mercado internacional acarretando, assim, certa inviabilidade na exploração da scheelita, tendo em vista que os custos para a exploração da mesma eram caros e o retorno já não era mais tão atrativo para continuar o trabalho. Também foi observado outras variáveis que influenciaram para a decadência da exploração, tais como: a atuação da China, exportando grandes quantidades de concentrado de minério de tungstênio, acarretando um excesso de oferta no mercado internacional; a oferta de produtos intermediários, como o ferro-tungstênio e o paratungstato de amônia-APT, a preços menores que os de concentrados, proporcionando um aumento nestas transações comerciais; reciclagem de sucatas de tungstênio e o uso de produtos cerâmicos como material de corte em substituição ao carboneto de tungstênio.

O Rio Grande do Norte é o detentor da maior concentração de scheelita do Brasil, estando em $4^{\circ}$ colocado na produção de recursos minerais do país. A exploração no Estado iniciouse na década de 1940 estimulada pelos Estados Unidos da América, que procuravam minério de tungstênio, dentre outros minerais. Em 1970 o RN atingiu seu ápice de exploração. O Estado já possuía em torno de 14 minas, fora os garimpos existentes. Uma das minas que se destacaram no período, sendo a maior do setor foi a Mina Brejuí.

Diante do cenário de desvalorização da scheelita no cenário internacional, a Mina também sofreu com esse ambiente desfavorável de exploração e exportação do mineral. A Mina Brejuí ficou paralisada, servindo como, nos últimos anos, o maior parque temático do Rio Grande do Norte, sendo visitada diariamente por turistas e estudantes vindos de toda parte do Brasil e do Exterior. Agora esse quadro de abandono no processo exploratório é passado. A mineradora retomou sua exploração, bem como exportação de scheelita.

Diante de todo o exposto acima, este trabalho objetiva traçar uma linha de conexão entre a gestão empresarial da mineradora e a sua retomada na exportação da scheelita, através de um estudo de caso com a Mineradora Tomaz Salustino S/A.

É percebido cada vez mais a necessidade de mudança, levando em consideração a dinamicidade, complexidade e crescimento que o mundo, os mercados possuem. Mundo e mercados que trazem consigo novos desafios para as organizações que estão inseridas nesse contexto. Vêem-se em muitas organizações várias modificações na sua estrutura para que as mesmas possam se adaptar.

Existem dois tipos de relacionamento dentro da organização. O formal, representa o relacionamento entre os recursos na forma projetada pela administração, enquanto o informal representa o relacionamento social baseado nos relacionamentos ou interesses compartilhados entre os diversos membros de uma organização. (CERTO E PETER: 1993)

Para toda e qualquer ação que a diretoria deseje implementar, como, por exemplo, à estratégia de negócios, deve-se considerar essas duas estruturas, a informal e formal. Observando que se alguma dessas duas formas de relacionamento não se adequar a nova estratégia, tornará inviável a aplicação da mesma, tendo em vista que a estratégia deve ser condizente com os requisitos impostos pelas duas estruturas. Têm-se mais dois requisitos para avaliar a implementação da estratégia, seria saber os níveis de administradores e as pessoas que são

\footnotetext{
${ }^{2}$ Dados disponíveis em www.minabrejui.com.br.
} 
responsáveis pela implementação e o uso da organização informal como meio de facilitar o acesso à implementação. (CERTO E PETER: 1993)

Dependendo do desenho estrutural que a organização tenha com a mudança, criação ou exclusão de um dos departamentos toda a estrutura da organização poderá ser afetada, tendo em vista os mais variados tipos de conexões existentes de setor com setor.

Toda empresa deve possuir um planejamento "do que será realizado" e "como será realizado" dentro da organização e fora dela pelos seus colaboradores/funcionários, expondo assim as incumbências de cada setor na execução de determinado processo.

Em outros termos, a empresa necessita definir um planejamento de ação através dos níveis da empresa - o institucional, o intermediário e o operacional, a partir da integração desses níveis. A empresa deve elaborar um plano básico de ação para alcançar seus objetivos. Sendo o planejamento a primeira função da administração, antes que qualquer função administrativa seja realizada. (CERTO E PETER: 1993).

Uma vez fixada a noção e compreensão do ambiente, suas variáveis e suas relações com a organização, procura-se estabelecer um modelo de gestão condizente com essa realidade.

A concepção do modelo de gestão incorporou-se a noção de compreensão do ambiente no qual a organização está inserida, dos seus traços comuns, de identificação das estratégias genéricas a que está sujeita. (TACHIZAWA E REZENDE, 2000).

Após a identificação dos traços, estratégias que a organização possui, bem como o ambiente no qual ela está inserida, é visto a necessidade da utilização de alguma forma de gestão condizente com essa realidade. Pode-se escolher dentre várias teorias de gestão, mas sempre atentar se a mesma irá se encaixar no perfil da organização.

É visto na atualidade teorias modernas, técnicas e estratégias emergentes de gestão. Dentre as quais são: Administração Estratégica, Administração Empreendedora, Administração Japonesa, Administração Virtual, Administração Participativa, a Reengenharia, o Benchmarking, a Terceirização, dentre outras.

A Mineradora Tomaz Salustino S/A esta localizada no município de Currais Novos desde 1943, fundada pelo Desembargador Tomaz Salustino. Em virtude da demanda existente no mercado internacional da scheelita na época da fundação da mineradora, o Desembargador Salustino percebendo tal cenário, iniciou o processo de internacionalização do mineral por iniciativa própria.

No ano de 1998 a mineradora paralisou a exploração e exportação da scheelita por causa do baixo valor do minério no mercado internacional, o que tornava mais lucrativo importar o mineral do que tentar extraí-lo no país.

$\mathrm{Na}$ atualidade a Mineradora encontra-se em um cenário totalmente diferente daquele que ela viveu durante a década de 90. Partindo dos dados colhidos através de organismos federais, como o Departamento Nacional de Produção Mineral em 2006, foi visto a mudança da demanda no mercado internacional em relação à scheelita. $\mathrm{O}$ preço do minério elevou-se consideravelmente no mercado devido a China - a qual era quase detentora das exportações do produto - retrair a oferta do mineral no mercado internacional. Tal cenário contribuiu para que várias mineradoras que haviam paralisado o processo de extração retornassem a esse processo. 
Segundo o Diretor Administrativo-Financeiro, Rogério Barreto, a formação societária da Mineradora esta atualmente dividida entre doze quotas, entre os familiares do Desembargador Salustino. Sendo uma Sociedade Anônima de Capital Fechado.

Devido essa fragmentação do poder foi necessária a elaboração de um sistema que pudesse dar condições harmônicas para o efetivo controle da Empresa. Com esse intuito foi formada uma cadeia hierárquica flexível. Existe assim um Conselho Administrativo, o qual escolhe a Diretoria Executiva, sendo ela composta por um Diretor presidente, Diretor administrativofinanceiro e um Diretor comercial. Todas as decisões perpassarem pela aprovação do Conselho.

Para a elaboração do planejamento organizacional da organização pela Diretoria se faz necessário o conhecimento prévio e análises sobre os fatores inerentes a organização, como os ambientes: geral, de tarefa e interno, os quais afetam diretamente na execução desse plano.

No mesmo ambiente dos organismos regulamentadores, a ação da Empresa esbarra na política fiscal, a qual é considerada o principal entrave para o desenvolvimento da Mineradora, observando se a alta carga tributária que ela paga. Para esse interveniente, a Mineradora já solicitou um auxilio ao Governo, o Programa de Apoio Desenvolvimento Industrial (PROADI). Com a utilização desse programa a Empresa poderá pagar 25\% dos impostos no ato e os outros $75 \%$ poderão ser parcelados, o que favorecerá a utilização desse capital excedente para o desenvolvimento da atividade.

Observando mais internamente a Mineradora em suas variáveis controláveis, observou-se que no setor de Recursos Humanos há o envolvimento com questões de segurança, motivação, remuneração, treinamento, contratação, dentre outras. Há toda uma preocupação com a segurança, por parte da Mineradora, dos funcionários, observando que a atividade de mineração é de certa forma perigosa por haver o manuseio de máquinas pesadas, ambientes insalubres e o uso de explosivos.

Para um trabalho mais efetivo dos funcionários, tanto na questão de produtividade e capacidade técnica para o cargo, a Mineradora faz valer no momento das contratações dos mesmos dois aspectos fundamentais: exigências do cargo e a experiência. Favorecendo a contratação de colaboradores mais capacitados e familiarizados com o cargo que serão admitidos.

Após a observância de todos esses fatores exposto anteriormente, a Diretoria se utiliza do conhecimento e analise dos mesmos para poder esboçar suas Estratégias Organizacionais para responder aos objetivos da empresa. Embora a retomada da extração da scheelita pela Mineradora se deu de forma impetuosa, ou seja, não houve nenhum tipo de planejamento prévio para que pudessem retornar as atividades, Ela conseguiu retomar suas atividades com êxito.

Para poder lidar com todas essas variáveis a organização se utiliza de um mix de modelos de gestão, com o intuito de moldar-se as mais variadas facetas que o ambiente possui.

De uma forma geral, o respondente afirma que a Mineradora utiliza quatro modelos de Gestão Empresarial as quais Ferrera, Fonseca e Pereira (2002) citam em sua obra, sendo elas: a Administração Estratégica, Administração Participativa, Administração Japonesa e a Administração Empreendedora. 
Com a utilização desses quatro modelos de gestão os gestores podem focar vários objetivos ao mesmo tempo, procedendo de uma forma mais variável que proporcione um melhor resultado final. Pois segundo a exposição de Ferrera, Fonseca e Pereira (2002), cada uma delas tem uma expectativa diferente, porém que levam ao alcance do objetivo final da empresa. Alem desses modelos de Gestão, a Mineradora também se utilizou de Ferramentas de Gestão como o downsizing e benchmarking.

No momento da criação da Mineradora o Desembargador Salustino fez uso do benchmarking funcional, visto que o mesmo foi analisar a atividade de fabricação dos equipamentos necessários para a mineração em uma empresa norte-americana. O downsizing foi utilizado atualmente, proporcionando o achatamento dos níveis hierárquicos, deixando a Empresa com uma estrutura mais horizontalizada, favorecendo ao tramite das informações entre os setores. Com esse achatamento tornou as informações - discutidas em reuniões e através de diálogos informais - mais rápidas no alcance do seu destino e com uma menor quantidade de barreiras, favorecendo a eliminação das distorções das informações.

Observou se também que os gestores da empresa dão certa liberdade para os funcionários, possuindo um perfil democrático nas suas ações. Perfil esse que vai de oposto ao do Desembargador Salustino, pois sua gestão era centralizada. Centralização essa sendo comum em Empresas Familiares, pois as mesmas são erguidas pela entidade do chefe da família, o pai. Ficando assim a mercê de um domínio Patriarcal no início de suas atividades, mas com o passar do tempo essa gestão vai se modificando, pois não há mais a presença do patriarca na empresa.

Um grande problema para empresas familiares seria o desmonte das mesmas pelos filhos e netos do fundador, pelo fato dos mesmos não se interessarem pelo negócio ou/e discórdias internas na família. Porém com a Mineradora não ocorreu isso. Além de a Empresa permanecer na sua atividade inicial e com os mesmos objetivos, vê-se a participação de todos os sócios no processo de gestão, denotando assim o interesse contínuo da família com a Mineradora.

A Mineradora Tomaz Salustino possui uma estrutura capaz de se destacar com maior relevância no mercado internacional, basta ter um planejamento coerente e plausível para isso. É valido salientar que a Mineradora não está em busca de lucros exorbitantes, a prova disso é sua exploração racional do minério, sem muita preocupação em ofertar em demasia. Porém ela omite-se em questões que são de relevância para poder dar sequiência, de uma forma mais acertada e eficiente, de suas atividades.

Em primeiro plano está a carência de um Plano de Negócios. Desde o momento que a Mineradora retomou suas atividades não foi elaborado um. É sabido que a formatação de um Plano de Negócios para todo e qualquer empreendimento se faz necessário para que se possa moldar e direcionar a organização para o alcance de determinado objetivo.

Pode-se esboçar aqui algumas sugestões para a Mineradora visando possíveis melhorias no processo e na organização.

Uma das sugestões propostas a Empresa é que a mesma deve iniciar as pesquisas e estudos referentes à diversificação da sua pauta de produtos. Partindo do princípio que a Mineradora paralisou suas atividades por causa de seu único produto ter entrado em crise, se faz necessário investir em novos produtos para não correr o risco de acontecer novamente tal fato. 
Um dos principais fatores para o encarecimento da scheelita é a logística interna. Portanto a Mineradora poderia optar por fazer parecerias que investissem na empresa, visando a aquisição de novos maquinários que pudessem diminuir os custos, ou terceirizar o serviço logístico, contribuindo assim com a execução do enfoque da Mineradora, a exploração, e deixasse a mercê da empresa terceirizada a parte logística do processo.

Pode-se abstrair de todo o conjunto da obra que a gestão empresarial existente na Mineradora é bastante flexível e possuidora de um conjunto de várias teorias administrativas, contribuindo com um processo mais organizado do controle organizacional.

Possuidora de uma estrutura flexível e horizontalizada, viu-se que a comunicação entre os setores da Mineradora era repassada de forma rápida, limpa e eficaz através de reuniões e diálogos informais entre os colaboradores e os gestores. Sendo os últimos possuidores de um espírito empreendedor, dinâmico e moderno, contribuindo com o andamento da Empresa nesse novo cenário que ela esta inserida, em contradição com o qual ela viveu antes de sua paralisação.

Conclui-se que o cenário que a scheelita se apresenta influenciou na alavancagem das exportações da mesma pela Mina Brejuí, e não a gestão da Mineradora, observando que foi uma retomada feita sem planejamento. Porém a empresa está buscando se organizar para poder dar continuidade a sua atividade exploratória e exportadora. Tal constatação vem de encontro com o esclarecimento do objetivo inicial do estudo, o qual pretendia evidenciar quais as influencias da gestão da Mineradora sobre a sua retomada na exportação da scheelita.

\section{REFERÊNCIAS BIBLIOGRÁFICAS}

1. ARANTES, Nélio. Sistemas de gestão empresarial - conceitos permanentes na administração de empresas válidas. $2^{a}$ edição. São Paulo: Atlas, 1998.

2. BARRETO, Maria Laura. Mineração e desenvolvimento sustentável: Desafios para o Brasil. $3^{\text {a }}$ edição. Rio de Janeiro: CETEM/MCT, 2001.

3. BASTOS, Luís Othon e SOUZA, Sérgio Aves de. Aplicação do modelo multidimensional na análise de organizações: um estudo multicasos em empresas familiares. Revista Eletrônica de Gestão Organizacional, Volume 4, Número 4. Pernambuco: UFPE,2006.

4. BERNARDI, Luiz Antonio. Manual de empreendedorismo e gestão: fundamentos, Estratégias e Dinâmicas. São Paulo: Atlas, 2003.

5. CERTO, S.S.; PETER, J.P. Administração estratégica: planejamento e. implementação da estratégia. São Paulo: Makron Books, 1993.

6. CHIAVENATO, Idalberto. Empreendedorismo - dando asas ao espírito empreendedor. São Paulo: Saraiva, 2005.

7. DAFT, Richard L. Organizações: teorias e projetos. São Paulo: Pioneira Thomson Learning, 2002.

8. Departamento Nacional de Produção Mineral. Minerais industriais. <http://www.dnpm.gov.br/>. Acesso em: 15 de nov 2006. 
9. Desafio 21. A $\quad$ A empresa familiar competitiva. <http://notitia.truenet.com.br/desafio21/newstorm.notitia.apresentacao.ServletDeNotici a? codigoDaNoticia=613\&dataDoJornal=atual> . Acesso em: 23 de nov. 2006.

10. DORNELAS, José Carlos Assis. Empreendedorismo: Transformando Idéias em Negócios. 2. ed. Rio de Janeiro: Elsevier, 2005.

11. DRUCKER, Peter Ferninand. Inovação e Espírito Empreendedor ( Entrepreneurship): prática e princípios. São Paulo: Pioneira Thomson, 2002.

12. FERREIRA, Armando Leite. Rota de Navegação: Desafio SEBRAE. Rio de Janeiro: Expertbooks, 2006.

13. FERRERA, Ademir; FONSECA, Ana Carla Reis; PEREIRA, Maria Isabel. Gestão empresarial: de Taylor aos nossos dias - evolução e tendências da moderna administração de empresas. São Paulo: Pioneira Thomson Learning, 2002.

14. GIL, A. C. Métodos e técnicas de pesquisa social. São Paulo: Atlas, 1996

15. KOTLER, Philip. Administração de Marketing. Edição do Milênio. São Paulo: Prentice Hall, 2000.

16. LAKATOS, Eva Maria e MARCONI, Marina de Andrade. Medologia Científica. 3 ed. São Paulo: Atlas, 2000.

17. Mina Brejuí. História, Home e Produtos. 〈http://www.minabrejui.com.br〉. Acesso em: 15 de nov. 2006.

18. MORAIS, João Marcelo. Estrutura organizacional na empresa familiar - estilos gerenciais e satisfação dos funcionários. 2004. Monografia (Curso de Mestrado em Gestão e Desenvolvimento Regional) - Universidade de Taubaté, Taubaté - São Paulo. 2004.

19. PORTER, Michael E. Estratégia competitiva: técnicas para análise de indústrias e da concorrência. $7^{a}$ edição. Rio de Janeiro: Elsevier, 1986. $30^{\circ}$ reimpressão.

20. SEDEC, Secretaria de Desenvolvimento Econômico. Proadi beneficia empresa de mineração. Disponível em: <http://www.sedec.rn.gov.br/noticias.asp?idnoticia=8301>. Acesso em: 20 de nov. 2006.

21. TACHIZAWA, Takeshy: REZENDE, Wilson. Estratégia empresarial: tendências e desafios - um enfoque na realidade brasileira. São Paulo: Mackron Books, 2000.

22. VERGARA, Syllvia Constant, Projetos e Relatórios de Pesquisa em Administração. São Paulo, Editora Atlas 1997.

23. YIN, Robert K. Estudo de caso: planejamento e métodos. 2. ed. Porto Alegre: Bookman, 2001ARORA, M.L., BARTH, E., UMPHRES, M.B. Technology evaluation of sequencing batch reactors. Journal Water Pollution Control Federation, v.57, n.8, p. 867-875, ago. 1985. 